NBER WORKING PAPER SERIES

\title{
LOG-LINEAR APPROXIMATION VERSUS AN EXACT SOLUTION AT THE ZLB IN THE NEW KEYNESIAN MODEL
}

\author{
Gauti B. Eggertsson \\ Sanjay R. Singh \\ Working Paper 22784 \\ http://www.nber.org/papers/w22784
NATIONAL BUREAU OF ECONOMIC RESEARCH
1050 Massachusetts Avenue
Cambridge, MA 02138
October 2016

First Version: June 2015. We are grateful to Violeta Gutkowski, Neil Mehrotra, Kevin Proulx and Matthew Rognlie for detailed comments. We also thank the seminar participants at the SED Meeting 2015 for many useful suggestions. Remaining errors are our own. The views expressed herein are those of the authors and do not necessarily reflect the views of the National Bureau of Economic Research.

NBER working papers are circulated for discussion and comment purposes. They have not been peer-reviewed or been subject to the review by the NBER Board of Directors that accompanies official NBER publications.

(C) 2016 by Gauti B. Eggertsson and Sanjay R. Singh. All rights reserved. Short sections of text, not to exceed two paragraphs, may be quoted without explicit permission provided that full credit, including $\odot$ notice, is given to the source. 
Log-linear Approximation versus an Exact Solution at the ZLB in the New Keynesian Model Gauti B. Eggertsson and Sanjay R. Singh

NBER Working Paper No. 22784

October 2016

JEL No. E30,E50,E60

\begin{abstract}
$\underline{\text { ABSTRACT }}$
How accurate is a log-linear approximation of the New Keynesian model when the nominal interest rate is bounded by zero? This paper compares the solution of the exact non-linear model to the log-linear approximation. It finds that the difference is modest. This applies even for extreme events in numerical experiments that replicate the U.S. Great Depression. The exact nonlinear model makes the same predictions as the log-linear approximation for key policy questions such as the size and sign of government spending and tax multipliers. It also replicates well known paradoxes like the paradox of toil and the paradox of price flexibility. The paper also reconciles different findings reported in the literature using Calvo versus Rotemberg pricing.
\end{abstract}

Gauti B. Eggertsson

Department of Economics

Brown University

64 Waterman Street

Providence, RI 02912

and NBER

gauti_eggertsson@brown.edu

Sanjay R. Singh

Department of Economics

Brown University

64 Waterman Street

Providence, RI 02912

sanjay_singh@brown.edu 


\section{Introduction}

Short-term interest rate collapsed to zero in most of the advanced world following the crisis of 2008, which limited central banks' ability to stimulate spending. This shifted the focus of policymakers and researchers to fiscal policy. Some striking results emerge from a class of New Keynesian models, typically using the Calvo (1983) model of price frictions, see e.g. Eggertsson (2011), Christiano, Eichenbaum and Rebelo (2011), and Woodford (2011). ${ }^{1}$ Once the zero bound on the short term nominal interest rate (ZLB) is binding, and if the monetary authority cannot commit to future monetary policy, the multiplier of government spending is always larger than one and in some cases much larger than one. Another noteworthy result, see e.g. Eggertsson (2010), is that supply side policies such as labor tax cuts are contractionary at the ZLB (also known as the paradox of toil). While the former result appeared to resurrect old Keynesian orthodoxy, the latter one goes against much of the conventional wisdom in macroeconomics.

There has been growing skepticism about the accuracy of these results in the economic profession. The work cited above relies on log-linear approximations of all equilibrium conditions except it explicitly keeps track of the constraint that the short term nominal interest rate is bounded by zero. ${ }^{2}$ Braun, Körber and Waki (2016) report results from a non-linear calibration of a model with quadratic pricing frictions (based on Rotemberg 1982). They find that government spending multipliers are small and orthodox at the ZLB, while the paradox of toil disappears. These results are of great interest, since the Calvo and the Rotemberg model are equivalent in their log-linear approximation. Fernández-Villaverde, Gordon, Guerrón-Quintana and Rubio-Ramirez (2015) study the non-linear Calvo model and emphasize the importance of non-linear features brought about due to the ZLB. A key contribution of their work is to consider richer structure for uncertainty than the previous literature, which clarifies several important non-linear properties implied by the ZLB that the previous literature did not capture. Miao and Ngo (2016) compare the fully non-linear Calvo model with the Rotemberg pricing model under uncertainty and document that these two models behave very differently in a non-linear setting. Taken together, these papers raise doubts about the accuracy of the existing literature that relies on log-linearizations, about the effect of fiscal policy at the ZLB.

One difficulty in making an overall assessment about the accuracy of the log-linearization in papers such as Eggertsson (2011), Christiano, Eichenbaum and Rebelo (2011), and Woodford (2011) on the basis of the work cited above, is that it either uses a different form of uncertainty, a different price mechanism (Calvo vs Rotemberg) or some combination of the two. This paper

\footnotetext{
${ }^{1}$ The first paper to formally study fiscal policy in the New Keynesian model subject to the ZLB is Eggertsson (2001).

${ }^{2}$ It is not important if the bound is exactly zero, or slightly positive or negative. The key is that there is $a$ bound.
} 
fills this gap.

The main finding of this paper is that the difference between solving the fully non-linear model or using a log-linear approximation (but taking account of the non-linearity created by the ZLB) is small in the numerical experiments. The exact non-linear Calvo model is solved and compared to a log-linear approximation, using the same form of uncertainty as in Eggertsson (2011), Christiano, Eichenbaum and Rebelo (2011), and Woodford (2011), i.e. a two state Markov Process with an absorbing state. Moreover, exactly the same procedure is used to parameterize the size of the shocks and parameters in the log-linear and non-linear settings.

Table 1: Multipliers at the ZLB

\begin{tabular}{|l|l|l|l|l|}
\hline Calibrations & GD in Non-Linear & GD in Linear & GR in Non Linear & GR in Linear \\
\hline$\frac{\partial \hat{Y}}{\partial G}$ & 2.3785 & 2.2168 & 1.2991 & 1.1828 \\
\hline$\frac{\partial \hat{Y}}{\partial \tau^{w}}$ & 0.7087 & 0.9953 & 0.1100 & 0.1499 \\
\hline
\end{tabular}

The bottomline is summarized in Table 1 that considers two benchmark parameterizations. One numerical experiment matches a recession of the order of the Great Recession (GR) (an output gap of -10 percent and a two percent fall in inflation). The other experiment matches a large contraction of the order of the Great Depression (GD) (30 percent output gap and a 10 percent drop in inflation). As the table reveals, there is little difference between the loglinear approximation of the model and the exact non-linear solution: the government spending multiplier is above one in the GR scenario and above 2 in the GD scenario as in Eggertsson (2011). In addition, the paradox of toil does not depend on the log-linear approximation, it occurs in either setting.

Overall, the results suggest that the log-linear approximation is not driving the often cited results of fiscal policy in New Keynesian model at the ZLB. The key non-linearity to keep track of is the ZLB, while the remainder of the model appears to be well approximated with log-linear approximation, at least under the assumption of a two state Markov process with an absorbing state. This does not, however, imply that there are no important non-linearities created by richer stochastic structure for the shocks at the ZLB, as documented by Fernández-Villaverde et al. (2015).

The assumption that uncertainty is captured by a two state Markov process with an absorbing state implies that the model can be collapsed into only two equations (aggregate demand and aggregate supply) in two unknowns (inflation and output). This makes the computation of the equilibrium in the non-linear model simple. An important assumption that allows this characterization is industry-specific labor markets as in Eggertsson and Woodford (2003). This 
assumption eliminates price dispersion as a state variable. ${ }^{3}$ Fernández-Villaverde et al. (2015) and Miao and Ngo (2016), however, assume a common labor market from which all firms must hire, in which case price dispersion is a state variable of the non-linear model. Consequently a simple two equation characterization of the form presented in this paper is not possible (see Woodford (2003) for a general discussion of the importance of this assumption in New Keynesian models).

Another important assumption maintained in this paper is that the fiscal policy intervention is perfectly correlated with the shock that drives the economy to the ZLB, i.e. the fiscal stimulus is in response to the recession. As emphasized in Eggertsson (2011), fiscal policy has a very different effect if it follows a different stochastic process than the shock that drives the economy to the ZLB. To take an extreme example, Eggertsson (2011) characterizes analytically when the government increases spending permanently at the ZLB. In this case the fiscal multiplier changes signs and becomes negative. Being explicit about the correlation of government spending with the underlying ZLB shock process is an important consideration to reconcile results reported in the literature that may sometime seem to conflict each other.

Finally, the main focus in this paper is the analysis of ZLB equilibrium that arises due to real shocks that lead to the ZLB being binding. The paper does not analyze equilibria that arise due to self-fulfilling expectations, but these type of equilibria can arise whether or not the model is log-linearized. There is a rich literature exploring this topic, an important recent contribution includes Christiano, Eichenbaum and Johannsen (2016). ${ }^{4}$ Christiano, Eichenbaum and Johannsen (2016)'s results suggest that the equilibria that arise due to self-fulfilling expectations can plausibly be ruled out via stability-under-learning criteria. ${ }^{5}$

While the log-linearization approximates the non-linear model at the ZLB quite well, when an equilibrium exists, the non-linear variation of the model also offers some additional insights that are briefly commented on below where the organization of the paper is outlined, with more details to follow.

Section 2 states the non-linear Calvo model. Section 2.1 clarifies the role of industry specific labor markets. While the framework is standard, it is useful to clarify why price dispersion does

\footnotetext{
${ }^{3}$ This modeling assumption is relatively standard in the New Keynesian literature, see e.g. Woodford (2003) for the textbook treatment. However, as stressed by Benigno and Woodford (2004), price dispersion is needed for welfare analysis and hence will feature as a state variable in the analysis of optimal monetary policy.

${ }^{4}$ Aruoba, Cuba-Borda and Schorfheide (2016), Benhabib, Schmitt-Grohé and Uribe (2001), Christiano and Eichenbaum (2012), Mertens and Ravn (2014), Nakata and Schmidt (2015) and Schmitt-Grohé and Uribe (2016), are some examples of important contributions in this literature. We do show, however, that the non-linear model exhibits multiple equilibria of a different form when the zero lower bound is binding, but we restrict attention to the locally determinate equilibrium, which allows us to do comparative statics and address questions related to multipliers.

${ }^{5}$ While their main focus is on ruling out multiplicity they also report numerical results on government spending multipliers in a Calvo model with common factor market for labor. Their numerical experiments deliver similar results across the linear and non-linear model. This suggests that the assumption of industry specific labor market, while helpful for tractability, is not driving the results reported in this paper.
} 
not appear in the definition of equilibrium. Section 2.2 summarizes the non-linear model by two equations in two unknown, i.e. output and inflation, given fiscal policy and an exogenous shock that follows a two state Markov process. This section shows that the non-linear model typically has two solutions, the "regular ZLB" which is similar to the one analyzed in the log-linearized models, and a hyper-deflation equilibrium. As already noted, the paper does not consider the case in which the ZLB is binding due to self-fulfilling expectations, which represents a third possibility. The hyper-deflation equilibrium appears less interesting than the "regular ZLB" as it is shown not to pass standard equilibria selection criteria like local-determinacy and learnability, in which case comparative statics are less meaningful. ${ }^{6}$ Accordingly the paper focuses on the "regular" ZLB equilibria and leaves the study of indeterminate hyper-deflation equilibrium to future work. Section 3 documents, in line with the literature that relies on log-linearization, that the drop in output is increasing in the persistence of the shock. However, while at some critical value the equilibrium in the log-linearized model "explodes" and then becomes indeterminate, the analog in the non-linear model is a finite drop in output which is followed by non-existence of equilibria. This gives a new rationale for the relative slope condition of the aggregate demand and aggregate supply, discussed in Eggertsson (2011). Section 4 compares the quantitative predictions of the log-linear approximation and the exact solution, i.e., what underlies Table 1 and explains the way in which the model is parameterized. Finally, section 5 clarifies why the non-linear Calvo model behaves so differently from the non-linear Rotemberg model documented in Braun, Körber and Waki (2016) and Miao and Ngo (2016). The key reason is that in the Rotemberg model, large deflation implies very large resource cost of price adjustment. The resource costs of price changes become implausibly large very quickly (over 100\% of GDP for 10\% deflation) suggesting that the model with Rotemberg price adjustment costs cannot generate the Great Depression. Motivated by Rotemberg's original article, this section concludes by suggesting an alternative interpretation of these costs (as in Ascari and Rossi (2012)) so that these costs do not show up directly in the resource constraint. The section documents that under this alternative interpretation the Calvo and the Rotemberg model behave similarly at the ZLB.

\footnotetext{
${ }^{6}$ When an equilibrium is indeterminate in the model it means that there is an infinite number of bounded equilibria that solve the equations of the model in the vicinity of that equilibrium This means that comparative statics are not meaningful absent further assumptions, for it becomes arbitrary which equilibria to select in response to an exogenous disturbance.
} 


\section{Non-linear Calvo Model at the ZLB}

\subsection{Basic Model}

This section briefly outlines the textbook (Woodford, 2003) New Keynesian model highlighting the relevance of industry specific market for wages. It concludes with a proposition summarizing that the model does not have any endogenous state variable, provided that monetary policy is purely forward looking. The representative household maximizes

$$
\mathbb{E}_{0} \sum_{t=0}^{\infty} \beta^{t} \xi_{t}\left[\frac{C_{t}^{1-\tilde{\sigma}^{-1}}}{1-\tilde{\sigma}^{-1}}-\lambda \frac{\int_{0}^{1} n_{t}(i)^{1+\omega} d i}{1+\omega}\right]
$$

where $C_{t}$ is a Dixit-Stiglitz aggregate

$$
C_{t}=\left[\int_{0}^{1} c_{t}(i)^{\frac{\theta-1}{\theta}} d i\right]^{\frac{\theta}{\theta-1}}
$$

with $\theta>1, n_{t}(i)$ is the quantity of labor supplied of type $i, \omega>0$ is the inverse of the Frisch elasticity of labor, $\lambda$ a normalizing constant and $0<\beta<1$ the discount factor.

The household demand for good $i$ is

$$
c_{t}(i)=C_{t}\left(\frac{p_{t}(i)}{P_{t}}\right)^{-\theta}
$$

where $p_{t}(i)$ is the price of good $i, P_{t}$ is the price level given by

$$
P_{t} \equiv\left[\int_{0}^{1} p_{t}(i)^{1-\theta} d i\right]^{\frac{1}{1-\theta}}
$$

so that $P_{t} C_{t}=\int_{0}^{1} p_{t}(i) c_{t}(i) d i$.

The households trade in one-period risk-free nominal bonds $B_{t}$ that pay $1+i_{t}$ in the next period where $i_{t}$ is the nominal interest rate. ${ }^{7}$ The period flow budget constraint is:

$$
\int_{0}^{1} p_{t}(i) c_{t}(i) d i+B_{t} \leq\left(1+i_{t-1}\right) B_{t-1}+\left(1-\tau_{t}^{w}\right) \int_{0}^{1} w_{t}(i) n_{t}(i) d i+\int_{0}^{1} Z_{t}(i) d i-T_{t}
$$

where $w_{t}(i)$ is the nominal wage rate in the $i$ th industry in the economy, $Z_{t}(i)$ is the nominal profits from the sale of good $i, T_{t}$ are the lump sum taxes and $\tau_{t}^{w}$ is the payroll tax.

Every good $i$ is produced by a monopolistically competitive firm. The production function of

\footnotetext{
${ }^{7}$ It is not important here whether markets are assumed to be complete or if the only asset is a one period risk-free nominal bond, whose existence is needed to price the nominal interest rate which is the instrument of monetary policy. This is due to the representative household assumption.
} 
the firm is assumed to be linear in industry-specific-labor:

$$
y_{t}(i)=n_{t}(i)
$$

All production is consumed, so that $C_{t}=Y_{t}$, and each firm faces the demand function for its production given by $y_{t}(i)=Y_{t}\left(\frac{p_{t}(i)}{P_{t}}\right)^{-\theta}$.

The key assumption in Woodford (2003) is that the labor employed by each monopolistically competitive firm corresponds to a particular type of the labor variety supplied by the households. The firm takes this wage rate as given. The firm's period profit function is then given by

$$
\Pi_{t}(i)=p_{t}(i)\left(\frac{p_{t}(i)}{P_{t}}\right)^{-\theta} Y_{t}-w_{t}^{I}\left(\frac{p_{t}(i)}{P_{t}}\right)^{-\theta} Y_{t} .
$$

Woodford (2003) suggests that $w_{t}^{I}$ should be interpreted as an industry specific wage for good variety $i$. This wage rate can then be related to the price level of good $i$ in that industry via the first order labor condition of the household as $\frac{w_{t}^{I}}{P_{t}}=\frac{\lambda n_{t}(i)^{\omega} \tilde{C}_{t}^{\tilde{\sigma}^{-1}}}{\left(1-\tau^{w}\right)}=\frac{\lambda Y_{t}^{\omega}\left(\frac{p_{t}^{I}}{P_{t}}\right)^{-\theta \omega} C_{t}^{\tilde{\sigma}^{-1}}}{\left(1-\tau^{w}\right)}$ where $p_{t}^{I}$ is the industry-wide common price. Accordingly the period profit function of a firm producing good variety $i$ can be written as $\Pi\left(p_{t}(i), p_{t}^{I}, P_{t}, Y_{t}\right) .8$

Using the Calvo (1983) price-setting assumption, a fraction $0<\alpha<1$ of good prices remain unchanged in any period. With probability $1-\alpha$, a firm is selected at random (independent of the time of last adjustment) to adjust its good's price. Let $p_{t}^{*}$ be the optimal reset price in period $t$. A supplier that changes its price in period $t$ chooses its new price $p_{t}(i)$ to maximize present discounted value of its profits, taking as given the industry level wage $w_{t}^{I}$ which is expressed in terms of $p_{t}^{I}$ :

$$
\mathbb{E}_{t}\left\{\sum_{j=t}^{\infty} \alpha^{j-t} Q_{t, j} \Pi\left(p_{t}(i), p_{j}^{I}, P_{j}, Y_{j}\right)\right\}
$$

where $Q_{t, t+1}$ is the stochastic discount factor in period $t+1$ with respect to $t$. The first order condition for optimal price setting is:

$$
\mathbb{E}_{t}\left\{\sum_{j=t}^{\infty} \alpha^{j-t} Q_{t, j} \Pi_{1}\left(p_{t}^{*}, p_{j}^{I}, P_{j}, Y_{j}\right)\right\}=0
$$

\footnotetext{
${ }^{8}$ As noted by Woodford (2003), even if industry-specific labor markets are assumed, this need not imply that firms have monopsony power. Instead it can be assumed that each firm is a wage-taker as noted above. See page 148 in chapter 3 in Woodford (2003) for an elaboration on this point but where a more general notation is also developed to make this point clear: In short, assume a double continuum of differentiated goods, indexed by $(I, j)$, with an elasticity of substitution of $\theta$ between any two goods. Then all goods with the same index I (goods in the same "industry") are assumed to change their prices at the same time, all using the same type I labor. Gertler and Leahy (2008) use a similar structure to this double continuum, except they allow for idiosyncratic risk across firms within an 'island' (industry).
} 
Following (Woodford, 2003) all firms in industry I reset the price in period $t$ so this becomes:

$$
\mathbb{E}_{t}\left\{\sum_{j=t}^{\infty} \alpha^{j-t} Q_{t, j} \Pi_{1}\left(p_{t}^{*}, p_{t}^{*}, P_{j}, Y_{j}\right)\right\}=0
$$

This gives the closed form solution :

$$
\frac{p_{t}^{*}}{P_{t}}=\left(\frac{K_{t}}{F_{t}}\right)^{\frac{1}{1+\omega \theta}}
$$

where $F_{t}$ and $K_{t}$ are aggregate variables given by:

$$
\begin{gathered}
F_{t} \equiv \mathbb{E}_{t} \sum_{j=t}^{\infty}(\alpha \beta)^{j-t} \xi_{j} C_{j}^{-\tilde{\sigma}^{-1}} Y_{j}\left(\frac{P_{j}}{P_{t}}\right)^{\theta-1} \\
K_{t} \equiv \mathbb{E}_{t} \sum_{j=t}^{\infty}(\alpha \beta)^{j-t} \frac{\theta}{\theta-1} \frac{\lambda \xi_{j}}{\left(1-\tau_{j}^{w}\right)} Y_{j}^{1+\omega}\left(\frac{P_{j}}{P_{t}}\right)^{\theta(1+\omega)}
\end{gathered}
$$

To summarize, the following equations define the equilibria

1. Euler Equation

$$
1=\beta\left(1+i_{t}\right) \mathbb{E}_{\mathrm{t}}\left[\left(\frac{C_{t+1}}{C_{t}}\right)^{-1 / \tilde{\sigma}} \frac{\xi_{t+1}}{\xi_{t}} \frac{1}{\Pi_{t+1}}\right]
$$

2. NK Phillips Curve

$$
\begin{aligned}
K_{t} & =\frac{\theta}{\theta-1} \frac{\lambda \xi_{t}}{\left(1-\tau_{t}^{w}\right)} Y_{t}^{1+\omega}+\alpha \beta \mathbb{E}_{\mathrm{t}}\left[\Pi_{t+1}^{\theta(1+\omega)} K_{t+1}\right] \\
F_{t} & =\xi_{t} C_{t}^{-\frac{1}{\tilde{\sigma}}} Y_{t}+\alpha \beta \mathbb{E}_{\mathrm{t}}\left[\Pi_{t+1}^{(\theta-1)} F_{t+1}\right] \\
\frac{K_{t}}{F_{t}} & =\left(\frac{1-\alpha \Pi_{t}^{\theta-1}}{1-\alpha}\right)^{\frac{1+\omega \theta}{1-\theta}}
\end{aligned}
$$

3. Resource Constraint

$$
Y_{t}=C_{t}+G_{t}
$$

Finally, price dispersion at time $t$ is defined as

$$
\Delta_{t} \equiv \int_{0}^{1}\left(\frac{p_{t}(i)}{P_{t}}\right)^{-\theta(1+\omega)} d i
$$

To summarize:

Proposition 1. In a representative agent New Keynesian economy with industry-specific labor markets 
and Calvo price setting, an equilibrium is defined as a collection of stochastic processes for $\left\{C_{t}, Y_{t}, \Pi_{t}, K_{t}, F_{t}\right.$ \} that solve eqns $\left\{1\right.$ - 5\} given a path for $\left\{G_{t}, \tau_{t}^{w}\right\}$ determined by fiscal policy, a path for $\left\{i_{t}\right\}$ determined by monetary policy and a path for $\left\{\xi_{t}\right\}$. Price dispersion defined by eqn 6 does not feature as a state variable and is redundant in the determination of the equilibrium as long as it does not enter the governments' policy choices.

The reason price dispersion does not enter the determination of the endogenous variables is pointed out in Woodford (2003). The benchmark New Keynesian model assumes industryspecific labor markets so that the real marginal cost of supplying a given good depends only on $y_{t}(i)$ and aggregate output $Y_{t}$. Alternatively in a model in which each firm hires from an economy-wide labor markets, then the real marginal cost instead depends also on an alternative measure of aggregate output $X_{t}=\int_{0}^{1} y_{t}(i) d i$ which in turn depends upon price dispersion (Yun, 1996). ${ }^{9}$ Using industry-specific labor markets instead of economy-wide factor markets has important implications for real rigidities in the economy as stressed in Woodford (2003). It also allows for the analysis of the model without price dispersion as a state variable, as long as the government policy does not depend on price dispersion. For welfare evaluation, however, price dispersion is relevant, for it enters social welfare. Accordingly, optimal monetary policy will in general take price dispersion into account (see Benigno and Woodford 2004). In this paper, however, policy will be characterized by a strict inflation target without reference to any endogenous state variable, as in Eggertsson and Woodford (2003).

\subsection{Two state Markov Chain, the ZLB and AS and AD equations}

Closed form solutions for 'Aggregate Supply' and 'Aggregate Demand' can now be derived under the assumption that the exogenous variable can only take on two values. $\xi_{t}$ is a two-state Markov chain with an absorbing state. The long run, as in Eggertsson (2011), is when the shocks are at the non-stochastic steady state. The long run is an absorbing state. The short run, in contrast, is defined by period $t \geq 0$ at which time the shock $\xi_{S}$ takes on a value below its steady state value $\xi_{L}$. It is assumed that in each period $t<T^{e}$ when $\xi_{t}=\xi_{S}$ there is a constant probability $(1-\mu)$ that the shock reverts to its long run steady state value. $T^{e}<\infty$ is the stochastic (but finite) time period when the shock is back at the steady state level. So $t \geq T^{e}$ is defined as the long run.

The central bank sets an inflation target $\Pi_{t}=1$ whenever it can. If this inflation target implies negative nominal interest rate, then the central bank sets $i_{t}=0$ in which case $\Pi_{t}$ is

\footnotetext{
${ }^{9}$ Compare the intra-temporal condition of the household in the model with industry-specific labor markets with the economy-wide labor markets. $\frac{W_{t}}{P_{t}}$ depends on $N_{t}$ in the economy wide labor markets model, and this aggregate depends on the price dispersion. On the other hand, the factor-market-specificity assumption makes the real wage independent of this aggregate.
} 
endogenously determined. The analysis only considers the case in which the ZLB is binding due to fundamental shocks but does not consider the possibility that the ZLB is binding due to self-fulfilling expectations. Government spending and/or labor taxes can take on any values $G_{S}$ and $\tau_{S}^{w}$ in the short run but return back to steady state in the long run given by $G_{L}$ and $\tau_{L}^{w}$. There is perfect correlation of the fiscal policy intervention and $\xi_{t} \cdot{ }^{10}$

The system of equations can be simplified into two equations that determine inflation and output in the short run. Units are chosen so that in the steady state, i.e the long run, $Y_{L}=\xi_{L}=1$, implying that $\lambda=\left(\frac{\theta-1}{\theta}\right)\left(1-G_{L}\right)^{-\tilde{\sigma}^{-1}}\left(1-\tau_{L}^{w}\right)$. Furthermore, given equations (1)-(5) in the long run $\Pi_{L}=Y_{L}=1,1+i_{L}=\beta^{-1}, C_{L}=1-G_{L}$ and

$$
K_{L}=F_{L}=\frac{\left(1-\tau_{L}^{w}\right)\left(1-G_{L}\right)^{-\frac{1}{\tilde{\sigma}}}}{1-\alpha \beta}
$$

This allows for an explicit characterization of inflation and output in the short-run.

What makes the model particularly tractable is 1) that it is purely forward looking, and 2) the assumption of an absorbing steady state. This implies that (1)-(5) can be combined into an AS and an $\mathrm{AD}$ curve that determine $\Pi_{S}$ and $Y_{S}$. It is assumed that the shock $\xi_{S}$ is large enough so that the zero bound is binding, i.e., the solution $\Pi_{S}=1$ implies negative nominal interest rate. Accordingly, $i_{S}=0$.

1. AD curve: The Euler equation (1) and the Resource Constraint (5) define an AD relationship in the short run:

$$
Y_{S}=G_{S}+(1-\bar{G})\left\{\left[1-\beta \mu \Pi_{S}^{-1}\right] \frac{\xi_{S}}{(1-\mu) \beta}\right\}^{\tilde{\sigma}}
$$

2. AS curve: The New-Keynesian Phillips curve (2)-(4) and the resource constraint (5), define the AS curve in the short run:

$$
\frac{\frac{\theta}{\theta-1} \frac{\lambda \xi_{S}}{\left(1-\tau_{S}^{w w}\right)} Y_{S}^{1+\omega}+\alpha \beta(1-\mu) K_{L}}{\xi_{S}\left(Y_{S}-G_{S}\right)^{-\frac{1}{\tilde{\sigma}}} Y_{S}+\alpha \beta(1-\mu) F_{L}} \frac{1-\alpha \beta \mu \Pi_{S}^{(\theta-1)}}{1-\alpha \beta \mu \Pi_{S}^{\theta(1+\omega)}}=\left(\frac{1-\alpha \Pi_{S}^{\theta-1}}{1-\alpha}\right)^{\frac{1+\omega \theta}{1-\theta}}
$$

where $K_{L}$ and $F_{L}$ are given by (7).

Figure 1 plots up these two curves. ${ }^{11}$ Parameters are chosen as in Eggertsson (2011) to deliver

\footnotetext{
${ }^{10}$ As in Eggertsson (2011) we assume that lump-sum taxes adjust to clear the government budget constraint. Accordingly the evolution of government debt is irrelevant due to Ricardian equivalence.

${ }^{11}$ These equations are plotted as follows: For a given (fine) grid of numbers for Gross Inflation, AS and AD are just equations in one variable (Output). Find the values of Output that satisfy these equations at the grid points. It is straightforward for the AD equation. The AS equation is non-linear and so a non-linear optimization routine in Matlab 'fzero' is used to find the values of Output that satisfy the AS equation (starting from some initial value). A Web Appendix on the authors website provides more details on this algorithm and its robustness. In experiment there has always been found only one positive real value for $Y$ that satisfies the AS equation for a given $\Pi$.
} 
Figure 1: AS-AD representation in the non-linear Calvo

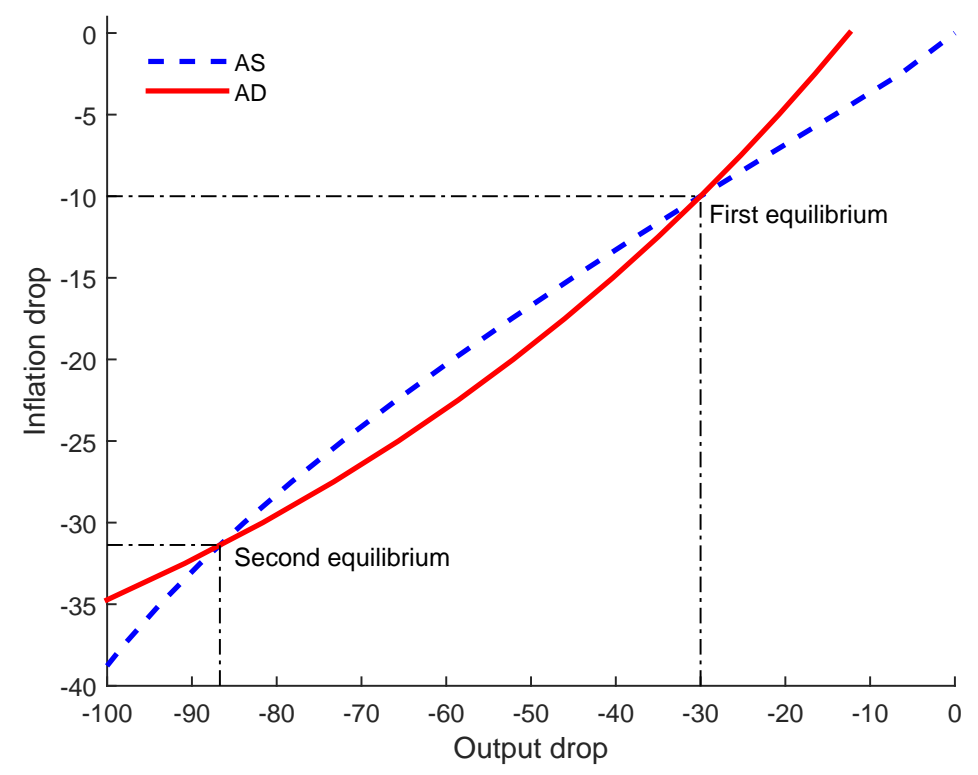

a Great Depression scenario of 30\% drop in output and 10\% drop in inflation where the two curves intersect. The parametrization is further discussed in section 4 .

The red (solid) line is the Aggregate Demand curve (8) for the case when the zero lower bound is binding. The dashed blue line is the Aggregate Supply curve (or the New Keynesian Phillips Curve) given by (9). There curves have two intersections. Moving from right to left, they are termed the First and the Second Equilibrium respectively.

The first equilibrium corresponds to a $30 \%$ output drop and $10 \%$ deflation. The second equilibrium, is a hyperdeflation equilibrium that generates $30 \%$ drop in prices per annum and over $80 \%$ drop in output. The first equilibrium is very similar to, and exhibits properties of the log-linear approximate equilibrium studied in the literature, such as Eggertsson and Woodford (2003). It is locally unique and determinate. The second equilibrium, however, is locally indeterminate. This means that for small perturbation there are infinitely many solutions that satisfy the equilibrium conditions. Moreover, it can be shown that indeterminate equilibrium is also not learnable/E-stable. ${ }^{12}$ Accordingly, the next subsection focuses on the determinate equilibria, leaving the analysis of second equilibrium to future work as its economic interpretation is less clear. ${ }^{13}$ As shown in Figure 2, the AS and AD curves are "almost linear" up to the stable equilibrium. The next section compares the solution obtained of the non-linear model to the solution from the log-linear approximation. It shows that the key qualitative prediction of the theory

\footnotetext{
${ }^{12}$ See McCallum (2007) for comparisons of E-Stability and determinacy criterions.

${ }^{13}$ Henceforth the figures display the comparative statics around the first equilibrium which is locally determinate. The Appendix describes how determinacy is established numerically. The Web Appendix on the authors website provide matlab codes that run the simulations to establish this.
} 
obtained from the log-linearized model still applies in the non-linear model.

Figure 2: The stable equilibrium in the non-linear Calvo model

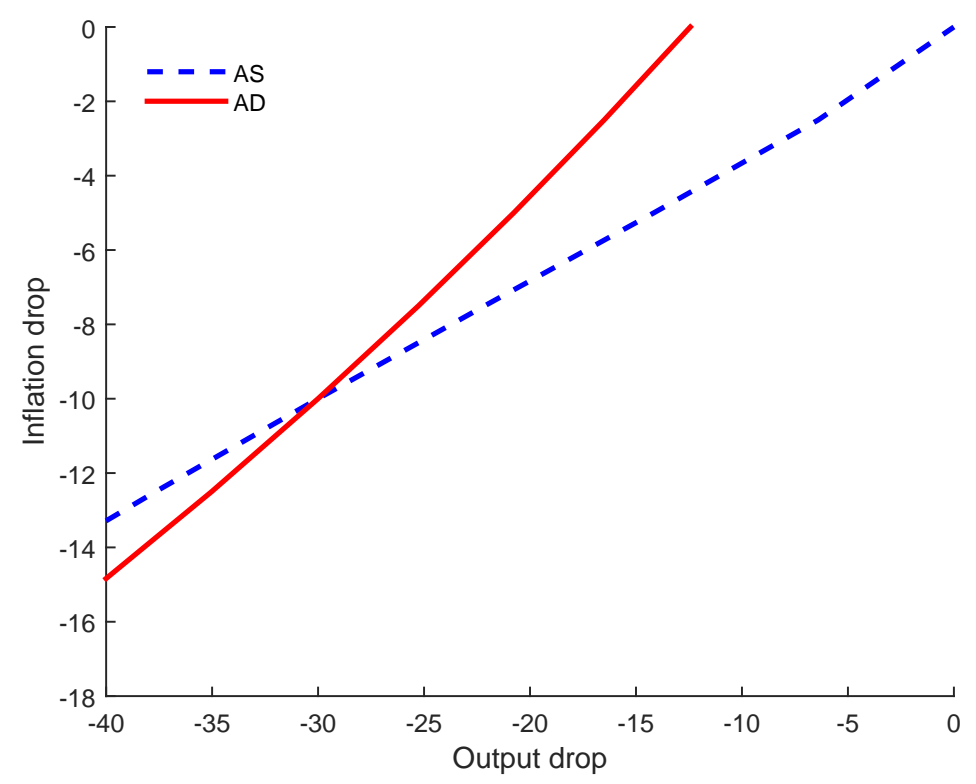

\section{Output drops at the ZLB in the non-linear and the linear model}

A key prediction of the log-linearized New Keynesian model is that for small shocks, there can be a large drop in output and inflation. This occurs due to a bifurcation. A natural first question is if this is an artifact of the log-linearization. This section confirms this phenomenon in the nonlinear model. As shown in Eggertsson (2011), the log-linearized model under the assumption of a two state Markov chain with an absorbing state can be expressed as:

1. Aggregate Demand

$$
\hat{Y}_{S}=\hat{G}_{S}+\frac{\sigma}{(1-\mu)}\left(\mu \pi_{S}-r_{S}^{e}\right)
$$

where $\hat{Y}_{S} \equiv \frac{Y_{S}-\bar{Y}}{\bar{Y}} ; \hat{G}_{S} \equiv \frac{G_{S}-\bar{G}}{\bar{Y}} ; \pi_{S}$

equiv $\Pi_{S}-1 ; r_{S}^{e} \equiv \log \beta^{-1}+(1-\mu) \log \xi_{S}$ and $\tilde{\sigma}=\sigma(1-\bar{G})$

2. Aggregate Supply

$$
\begin{gathered}
(1-\beta \mu) \pi_{S}=\kappa \hat{Y}_{S}+\kappa \psi\left(\chi^{w} \tau_{S}^{\hat{w}}-\sigma^{-1} \hat{G}_{S}\right) \\
\text { where } \chi^{w} \equiv \frac{1}{1-\bar{\tau}^{w}} ; \hat{\tau}_{S}^{w} \equiv \tau_{S}^{w}-\bar{\tau}_{w} ; \kappa \equiv \frac{(1-\alpha)(1-\alpha \beta)\left(\omega+\sigma^{-1}\right)}{\alpha(1+\omega \theta)} \text { and } \psi \equiv \frac{1}{\sigma^{-1}+\omega}
\end{gathered}
$$

Figure 3 plots the AS and AD curves for the exact non-linear Calvo model and compare the solution to a log-linear approximation. Both the exact model solution and the log-linear 
Figure 3: AS-AD: Exact and log-linear approximation
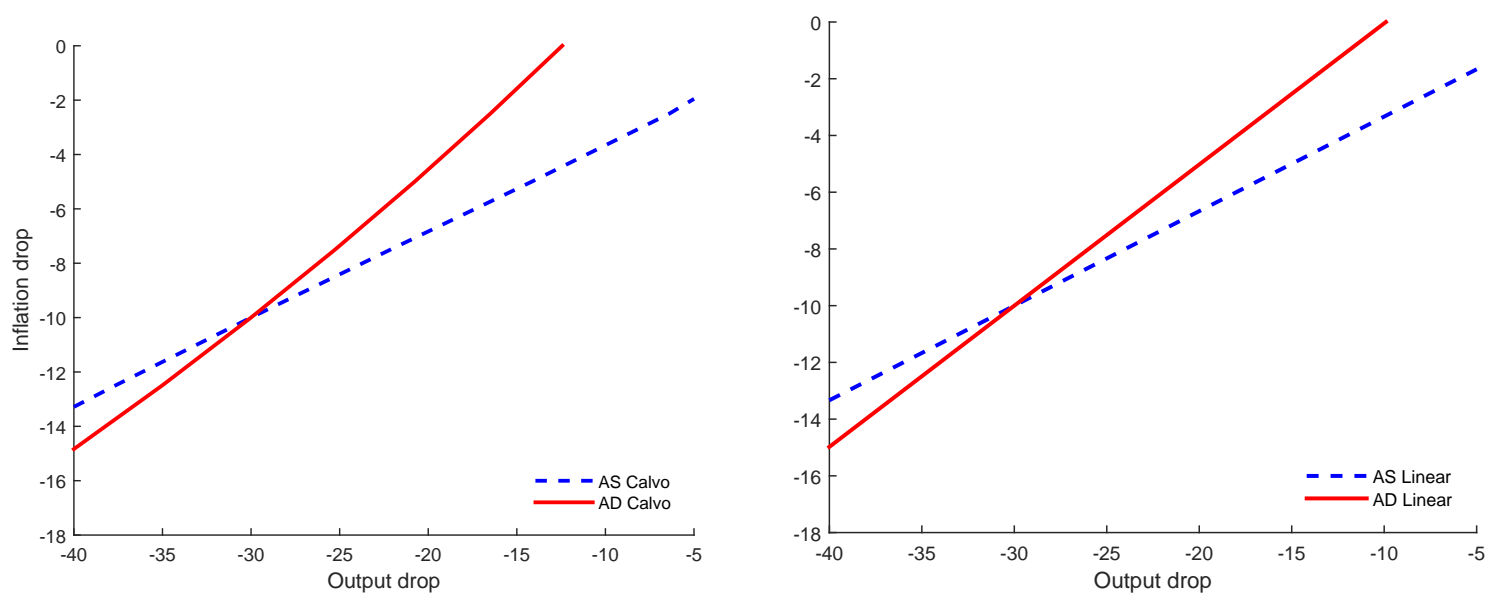

approximation are parameterized to generate a 30\% drop in output and 10\% drop in inflation at the intersection of the curves. The method used to parameterize the model is discussed further in Section 4, this section outlines features of the solution that do not rely on the particular parameterization, even if tying the model down with numbers is useful for illustration.

Let us first consider the log-linear approximation. Proposition 3 in Eggertsson (2011) establishes that the condition for local determinacy in the log-linear approximation of the model at the ZLB is

$$
L(\mu) \equiv(1-\mu)(1-\mu \beta)-\kappa \mu \sigma>0
$$

which says that the AD curve needs to be steeper than the AS curve. This will always be the case for a small enough $\mu$, i.e. if the probability of going back to "long run" is large enough. As the probability of staying in the depressed state increases, the two curves become close to parallel and the drop in output and inflation goes to $-\infty$. The log-linear approximation of the model exhibits an explosion at a critical value $\bar{\mu}$ at which point no solution exists (the lines are parallel). This is called the bifurcation point. When $\mu>\bar{\mu}$ there is indeterminacy in the loglinearized model. This explosive behavior is at the heart of the model. It explains how "small" shocks can trigger large drops in output.

The right hand side panel of figure 4 shows an example of the comparative static as $\mu$ is increased in the log-linear approximation of the model. This leads to larger output drop and larger deflation. The right hand side panel of figure 5 shows the exact bifurcation point in the log-linear approximation. The second and third rows of the right hand side of of figure 6 shows how output and inflation behave as a function of $\mu$. Output and prices drop without a bound as $\mu$ increases converging to $-\infty$ at the bifurcation point, which is not shown in the figure.

Let us now move to the exact non-linear model. Is this bifurcation only an artifact of the 
log-linearization? Recall that from figure 1 we are considering comparative statics of the first equilibrium, which is well behaved and determinate. In this equilibrium the relative slope of AD and AS are the same in the non-linear solution and the log-linear approximation as shown in 3. Figure 4 shows the effect of increasing the persistence of the shock in the non-linear model (left hand side) similarly leads to a larger recession in the non-linear model. The key difference between the non-linear and the log-linear approximation is show in figure 5. The bifurcation point occurs in the log-linear model (see right hand panel) when the linear AD and AS curves are paralell at $\bar{\mu}$. When $\mu>\bar{\mu}$ then the relative slope of the two lines is reversed, and the model is indeterminate. Meanwhile, we see that in the non-linear model there is also a critical value for two curves when they are tangent to each other as shown in the left hand side panel of figure 5. However, output and inflation do not explode at the bifurcation point. Instead, as seen in figure 6 , bifurcation occurs at $1-\mu=0.096$ where deflation is $18 \%$ and the output drop is $51 \%$. As can be seen in figure 5 this happens as the two curves no longer intersect, i.e. the AS curve is convex and is tangent to the AD curve, at finite values of output and inflation.

An interesting implication of this solution is that a marginal increase in $\mu$ beyond the bifurcation point implies that the non-linear model has no solution. Hence the indeterminacy region in the log-linearized model does not seem to be of much practical interest; in the non-linear counterpart the comparable region of the parameter space corresponds to non-existence of equilibria. The bound $\mathrm{C} 2$ on $\mu$ is, however, different for the nonlinear model. It is implicitly a condition requiring $\mu$ to be small enough so that two curves $\mathrm{AD}$ and $\mathrm{AS}$ are not tangent to each other. If that condition fails to be satisfied there is non-existence rather than indeterminacy. The remainder of the paper focuses on the case in which the model is away from the bifurcation point, so that an equilibrium exists, and analyzes the determinate equilibria in the non-linear model.

Figure 4: AS-AD: Comparative Statics with respect to $\mu$
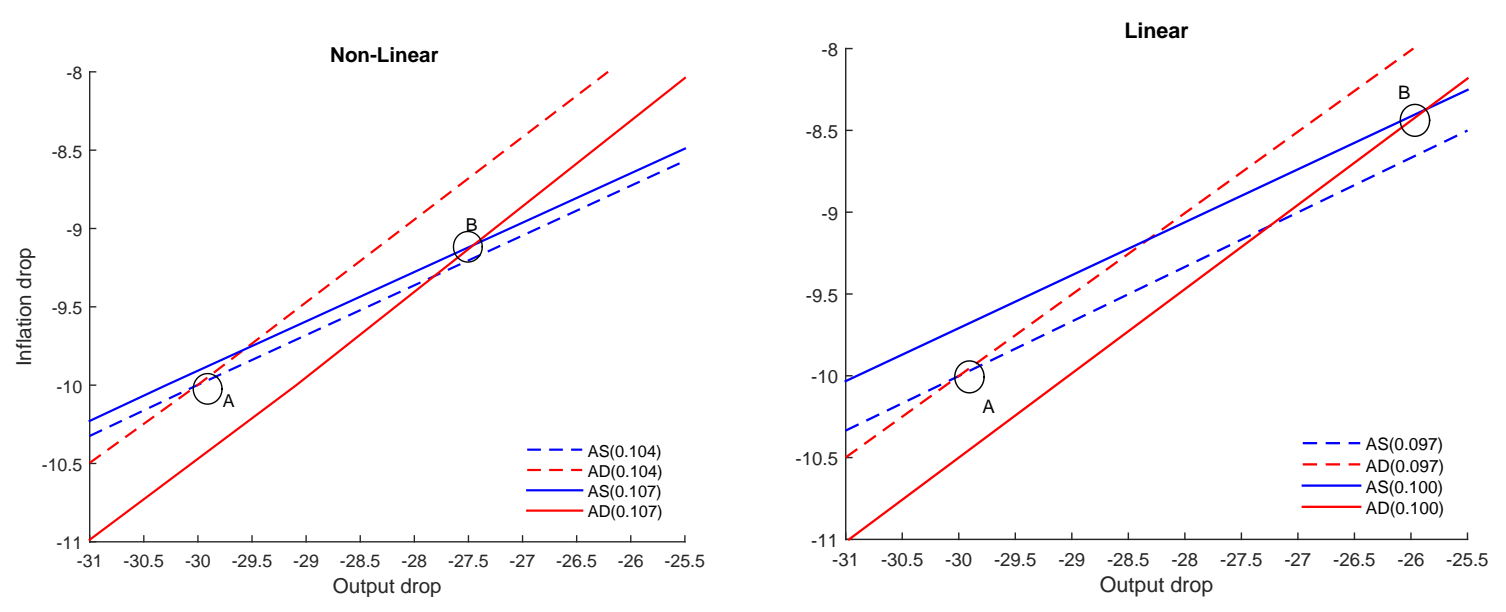
Figure 5: Bifurcation point: AS - AD
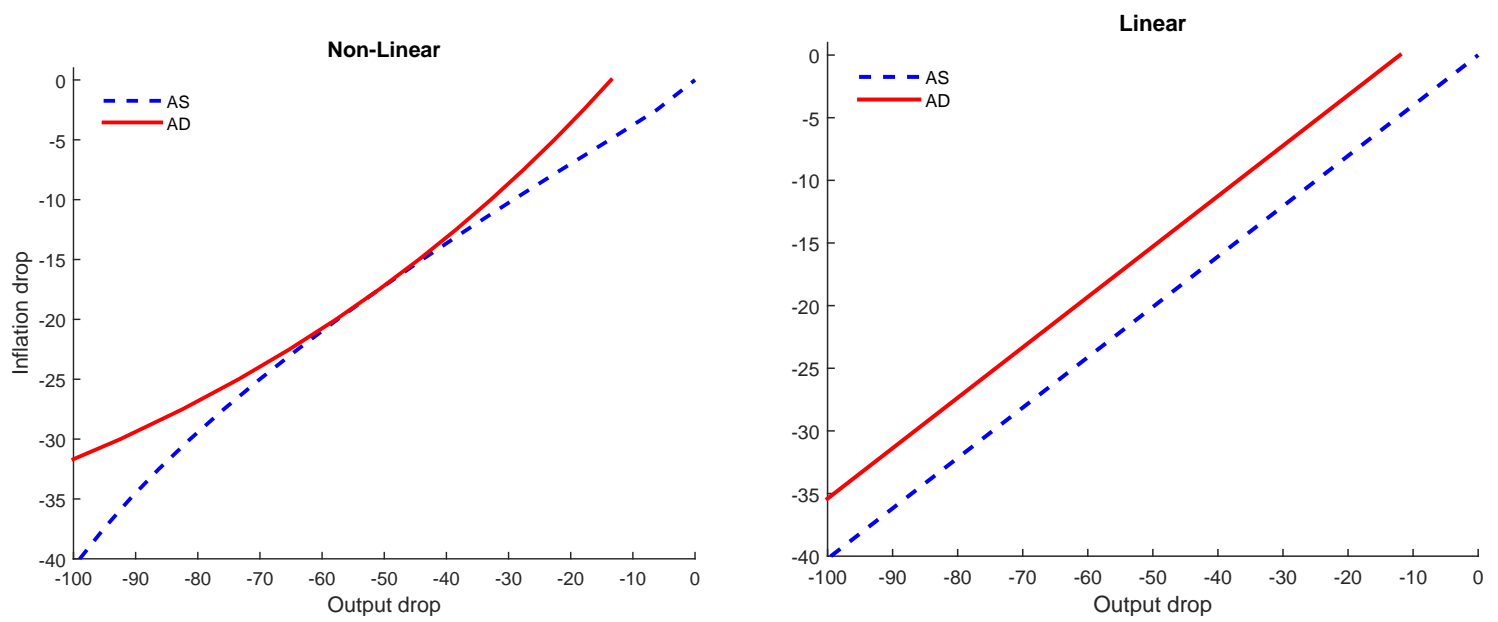

\section{Multipliers and paradoxes in numerical experiments}

This section first describes the parameterization in more detail for the two scenarios discussed in the introduction, then moves to analyze tax and spending multipliers.

The Great Depression scenario is defined as an event in which output drops by $30 \%$ and inflation (annual) by 10\%. The Great Recession is defined as a less extreme event with $10 \%$ drop in output and $2 \%$ drop in inflation. The parameters and shocks are chosen to maximize the posterior distribution of the model for both the linear and non-linear model. The priors are discussed and method for parameterization is discussed in detail in Denes and Eggertsson (2009) and are reproduced in the Appendix. The key focus of that Denes and Eggertsson (2009) is the sensitivity of the conclusions drawn to the choice of priors, while this paper's focus is on whether it matters if the exact or the log-linear approximation is used. The mode of the posterior of the model is reported in Table 2 for the exact model and the log-linear approximation. Observe from Table 2 that the exact choice of parameters and shocks needed to generate the GD and GR will depend on whether the parameterized is based on the exact non-linear model or its log-linear approximation. This, of course, should not be surprising. The interesting question is if, given the procedure for choosing the parameters, it matters if one uses the exact model vs. its log-linear approximation. Does this choice have any effect on the economic inference one draws once these two equilibrium characterizations have been used to replicate numerically a specific economic scenario (GR or GD). That is the focus of the remainder of this section. ${ }^{14}$

\footnotetext{
${ }^{14}$ This paper only reports the mode of the posterior. It is computed using a Matlab maximization routine developed by Christopher Sims. All codes used to construct the model and the figures in this paper are available on the authors' websites. The entire posterior distribution is not reported in this paper but this is done in Denes and Eggertsson (2009) for the log-linearized model using a Metropolis algorithm. The calibrated parameters for the linear model are the same as reported in Eggertsson (2011)
} 
Figure 6: Bifurcation point: Multipliers versus Exit probability
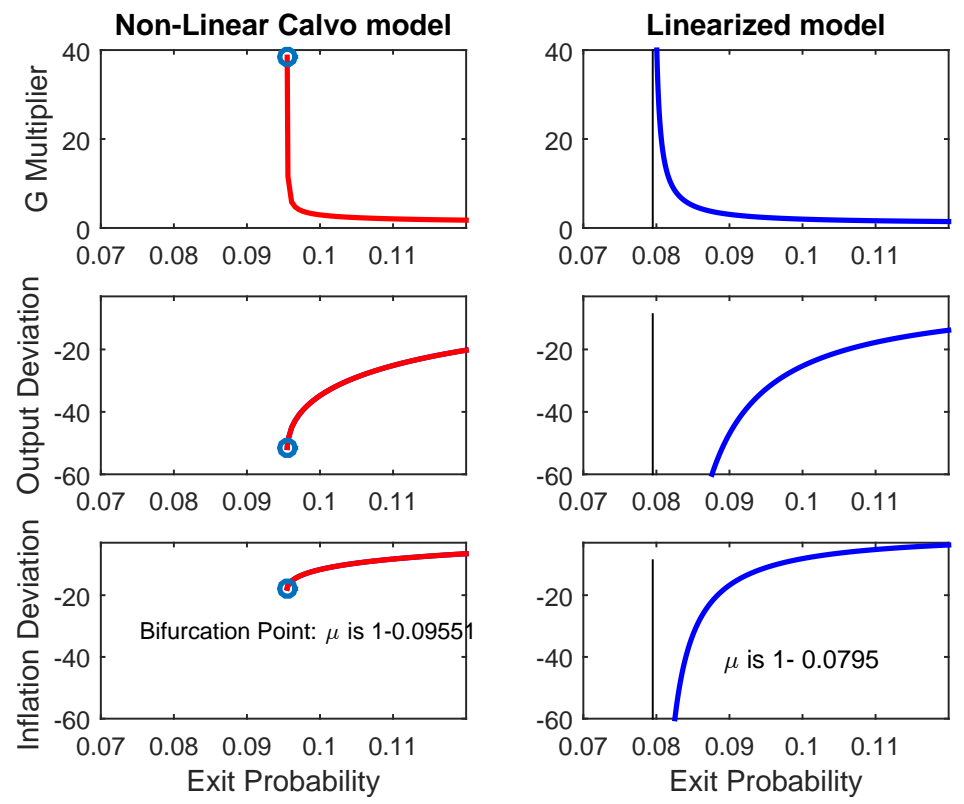

Table 2: Parameterizations under "Great Depression" and “Great Recession' scenarios'

\begin{tabular}{|l|l|l|l|l|}
\hline Scenario & \multicolumn{2}{|c|}{ Great Depression } & \multicolumn{2}{c|}{ Great Recession } \\
\hline \hline Model & Non-Linear & Linear & Non-Linear & Linear \\
\hline$\hat{Y}$ & $-30 \%$ & $-30 \%$ & $-10 \%$ & $-10 \%$ \\
\hline$\pi$ & $-10 \%$ & $-10 \%$ & $-2 \%$ & $-2 \%$ \\
\hline$\frac{\partial \hat{Y}}{\partial G}$ & 2.3785 & 2.2168 & 1.2991 & 1.1828 \\
\hline$\frac{\partial \hat{Y}}{\partial \tau^{w}}$ & 0.7087 & 0.9953 & 0.1100 & 0.1499 \\
\hline$\alpha$ & 0.7273 & 0.7721 & 0.7830 & 0.7871 \\
\hline$\beta$ & 0.9972 & 0.9969 & 0.9970 & 0.9970 \\
\hline$\sigma^{-1}$ & 1.0238 & 1.1649 & 1.3498 & 1.2900 \\
\hline$\omega$ & 1.8936 & 1.7465 & 2.4506 & 1.7415 \\
\hline$\theta$ & 12.2503 & 13.1190 & 15.7444 & 13.6012 \\
\hline $1-\mu$ & 0.1039 & 0.0965 & 0.0939 & 0.1393 \\
\hline$r_{S}^{e}$ & -0.0168 & -0.0111 & -0.0115 & -0.0136 \\
\hline
\end{tabular}

Rows 3 and 4 of Table 2 show the multipliers of government spending and labor tax cuts in the linear and the non-linear models at zero interest rate for the two numerical experiments. In the GD scenario the multiplier is 2.38 in the non-linear model, and 2.22 in the log-linear approximation. The tax-increase multiplier is 0.71 vs 0.99 . Hence both the large value of the government spending multiplier at the ZLB and the positive effects of tax increases at the ZLB (the paradox of toil) are maintained in the non-linear model. All the multipliers are smaller in the GR scenario, but the differences between the linear and non-linear model are of the same order. Figure 7 shows the comparative static of increasing government spending in the linear 
and non-linear model. Qualitatively the effects are the same, since the relative slopes of the two curves are the same, albeit the exact numbers differ. Even quantitatively, the effect of sizable government spending increases shown in figure 7 are not very different across the two models. ${ }^{15}$ Comparative statics for labor tax cut are shown in figure 8 , confirming the paradox of toil. ${ }^{16}$

Figure 7: Government Spending: Comparative Statics
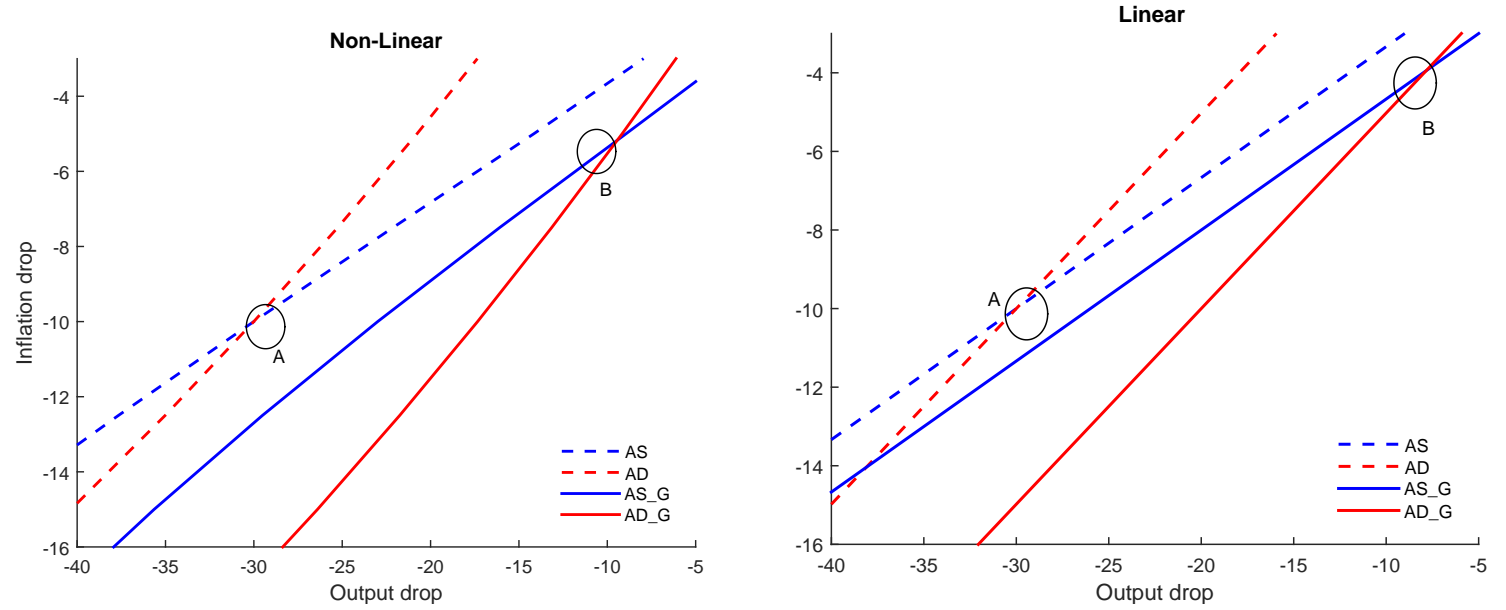

Figure 8: Tax Cut: Comparative Statics
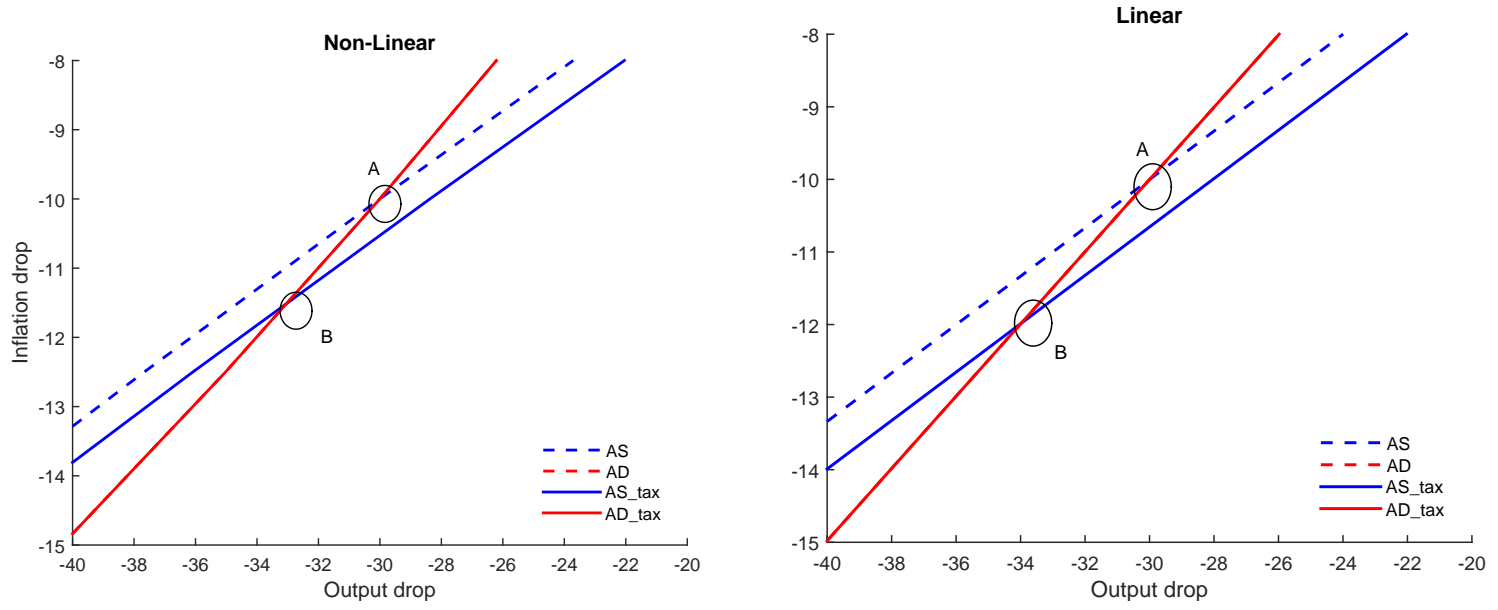

It is instructive to look at the behavior of the multiplier across the two models. The key economic insight of the literature that relied on log-linear approximation was that as the output drop becomes bigger, the government spending multiplier becomes larger. This phenomenon is shown in figure 6. In both models, as the probability of the staying at the zero bound increases, the drop in output intensifies. In the linearized model this means that the multiplier of govern-

\footnotetext{
${ }^{15}$ In the figure below, government spending is temporarily increased in both models from 20 percent of steady state output to 30 percent of steady state output

${ }^{16}$ In figure 8 the steady state payroll tax is temporarily reduced from its steady state of 30 percent of GDP to 26 percent of GDP.
} 
ment spending goes to $\infty$ as the drop in output goes to $-\infty$. In the non-linear model, however, bifurcation occurs at a finite level of output drop. At that point the multiplier of government spending is very large or about 40 .

Figure 9: Paradox of Flexibility
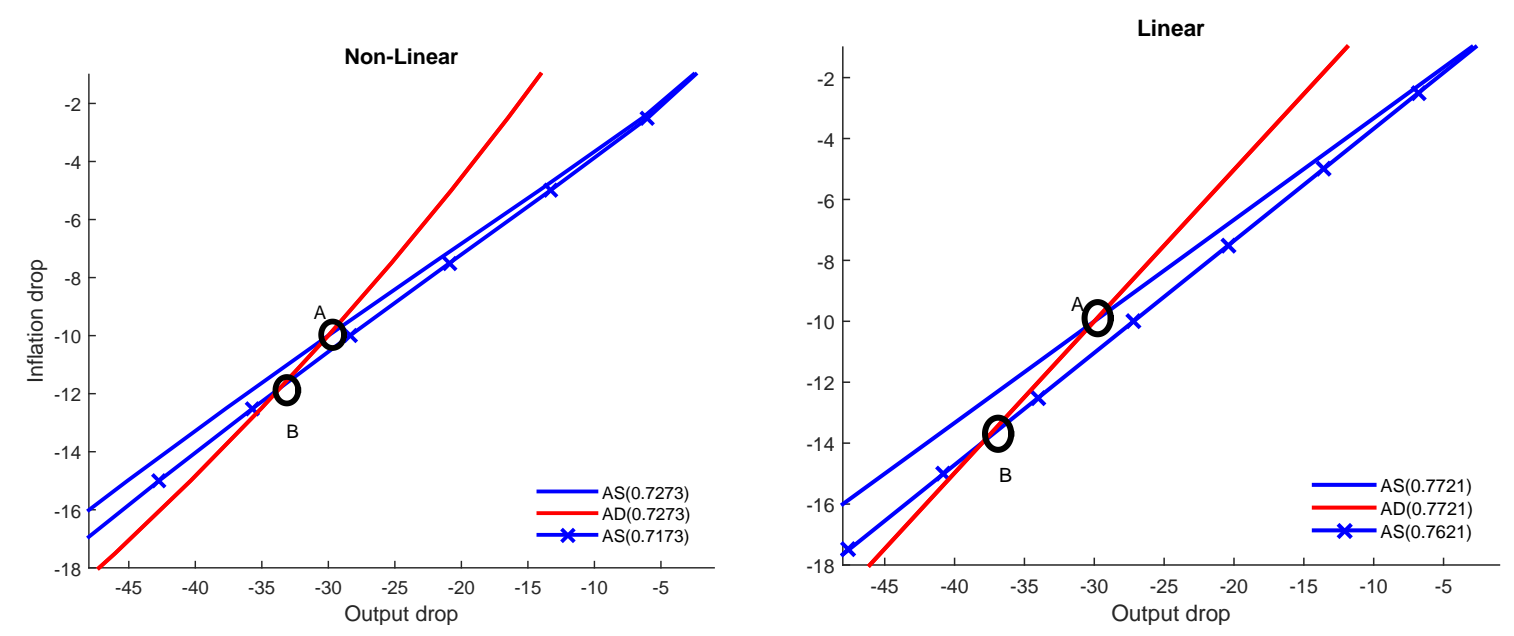

Notes: The parentheses show the value of $\alpha$ corresponding to the curves.

Figure 9 compares the two models for an increase in price flexibility. Only the AS curve is affected by change in price flexibility parameter. As prices become more flexible, more firms adjust them downward in response to a liquidity trap shock and hence more severe is the downturn. This perverse effect has been extensively explored in Eggertsson (2011) and Christiano, Eichenbaum and Rebelo (2011) among others and is confirmed in the non-linear model. This paradox is discussed in Bhattarai, Eggertsson and Schoenle (2014) in a more general setting away from the ZLB in an estimated DSGE model.

\section{Comparison to Rotemberg pricing}

Another prominently used price setting assumption is quadratic is due to Rotemberg (1982). The intermediate firms make the decision to change prices by incorporating the following cost of adjusting prices into their profit function:

$$
\frac{\alpha_{r}}{2}\left(\frac{P_{t}(i)}{P_{t-1}(i)}-1\right)^{2} Y_{t}
$$


The log-linearized Rotemberg and Calvo models coincide if the adjustment parameter is related to the Calvo price adjustment probability in the following way:

$$
\alpha_{r}=\frac{\alpha(\theta-1)(1+\omega \theta)}{(1-\alpha)(1-\alpha \beta)} .
$$

Following the same algebra as in the case of Calvo model, the following system of equations for the Rotemberg model can be derived under the same assumption about uncertainty and government policy as before.

1. Euler

$$
1=\beta(1-\mu)\left(\frac{1-\bar{G}}{C_{S}}\right)^{-1 / \tilde{\sigma}} \frac{1}{\xi_{S}}+\beta \mu \frac{1}{\Pi_{S}}
$$

2. NK Phillips Curve

$$
[1-\beta \mu]\left(\Pi_{S}-1\right) \Pi_{S}=\frac{\theta-1}{\alpha_{r}}\left(\frac{\theta}{\theta-1} \frac{\lambda C_{S}^{\tilde{\sigma}^{-1}} Y_{S}^{\omega}}{\left(1-\tau_{S}^{w}\right)}-1\right)
$$

where $\lambda \equiv \frac{\theta-1}{\theta}\left(1-\tau_{w}\right)(1-\bar{G})^{\tilde{\sigma}^{-1}}$.

3. Resource Constraint

$$
\begin{aligned}
& Y_{S}\left[1-\frac{\alpha_{r}}{2}\left(\Pi_{S}-1\right)^{2}\right]=C_{S}+G_{S} \\
& \text { where } \quad \alpha_{r}=\frac{\alpha(\theta-1)(1+\omega \theta)}{(1-\alpha)(1-\alpha \beta)}
\end{aligned}
$$

This system of equations can be simplified to yield a system of two equations (AD-AS) in two unknowns as before:

1. AD curve: The AD curve in the low state is derived from the the Euler equation and the Resource Constraint, together with the stipulation that the ZLB is binding:

$$
Y_{S}=\left[1-\frac{\alpha_{r}}{2}\left(\Pi_{S}-1\right)^{2}\right]^{-1}\left\{G_{S}+(1-\bar{G})\left\{\left[1-\beta \mu \Pi_{S}^{-1}\right] \frac{\xi_{S}}{(1-\mu) \beta}\right\}^{\tilde{\sigma}}\right\}
$$

2. AS curve: The AS curve in the low state is derived from the New-Keynesian Phillips curve and the recourse constraint:

$$
[1-\beta \mu]\left(\Pi_{S}-1\right) \Pi_{S}=\frac{\theta-1}{\alpha_{r}}\left(\frac{\theta}{\theta-1} \frac{\lambda\left\{Y_{S}\left[1-\frac{\alpha_{r}}{2}\left(\Pi_{S}-1\right)^{2}\right]-G_{S}\right\}^{\tilde{\sigma}^{-1}} Y_{S}^{\omega}}{\left(1-\tau_{S}^{w}\right)}-1\right)
$$

Figure 10 plots the AS and the AD curves for the non-linear Rotemberg model and compares 
Figure 10: Non-linear Rotemberg model vs its loglinearized approximation

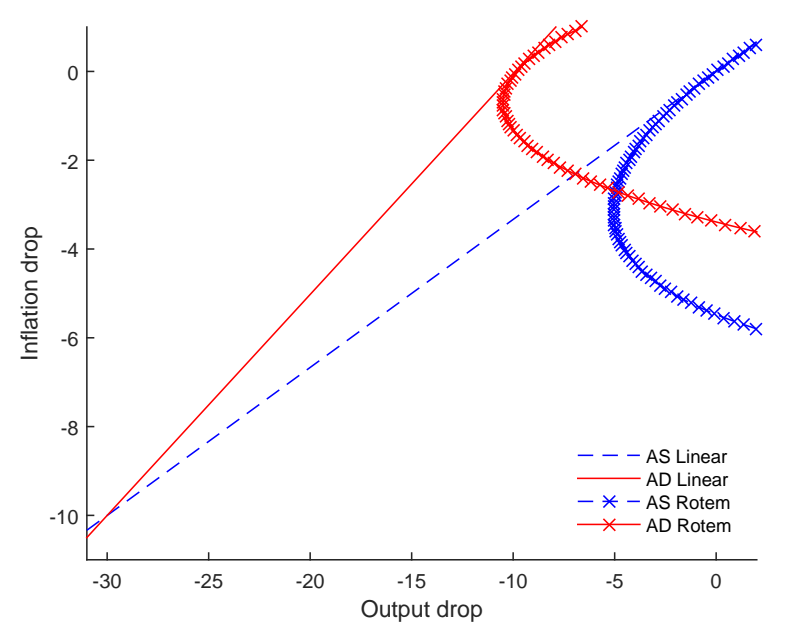

Figure 11: Resource Costs in the Rotemberg model

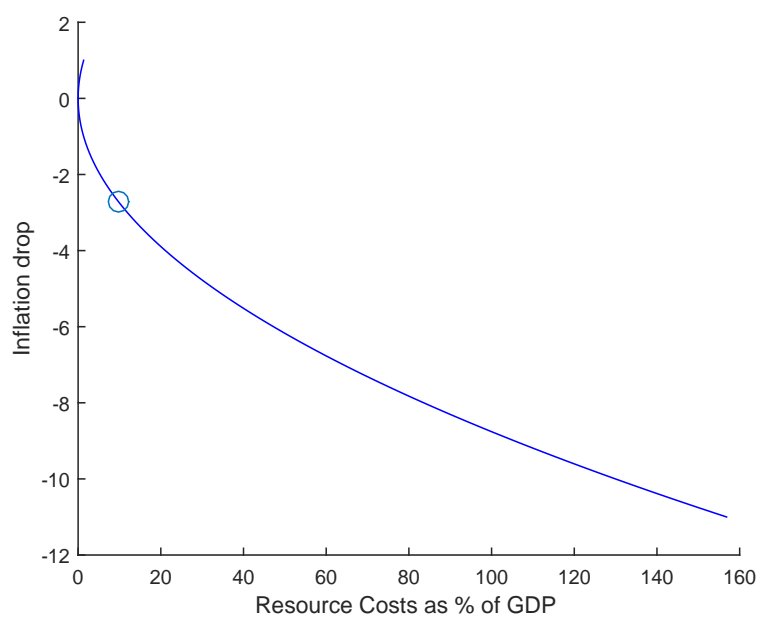

to the log-linear approximation assuming the following parameters. The log-linear Rotemberg model and the log-linear Calvo model are identical. Accordingly the the same parameterization is used for the log-linear Rotemberg model as in Table 2, using equation 10 to back out the relevant parameters for the log-linearized Rotemberg model. As figure shows this results in the same solution for the log-linear model as before, consistent with 30 percent drop in inflation and 10 percent drop in inflation. The non-linear Rotemberg model, however, cannot generate the GD. To illustrate why this is the case, the same parameterization is fed into the non-linear model and shown in the graph. From the figure, it is evident, that a fundamental divergence occurs between the linear and non-linear model.

As the figure reveals, the nonlinear Rotemberg model behaves in a fundamentally different way to the log-linear approximation. While the log-linear model generates a GD scenario, the non-linear Rotemberg model show a different equilibrium altogether. The two curves intersect at inflation drop of $2.70 \%$ and output drop of $4.95 \%$. More importantly, however, the AD curve has hanged its slope. If inflation goes below approximately $-1 \%$ then aggregate demand is now increasing with higher deflation, i.e., the larger the fall in the prices, the more output is demanded in the aggregate. This is in contrast to the non-linear and the log-linear approximation of the Calvo model discussed so far, as well as different from the log-linear approximation of the Rotemberg model.

Is this behavior of the non-linear Rotemberg model economically meaningful? Figure 11 sheds some light on this. It shows that as inflation goes down, more of the economy's resources go into changing prices. For example, a 10\% deflation as observed during the Great Depression would require over $100 \%$ of the output of the economy to change prices. Clearly then, by as- 
sumption, the Rotemberg model parameterized with physical resource costs of this kind cannot generate a Great Depression, a result also reported in Braun, Körber and Waki (2016). More generally, the large implied resource costs of changing prices is key to understanding why the $\mathrm{AD}$ curve changes its slope. To understand this, it is useful to write out the aggregate resource constraint

$$
Y_{S}=C_{S}+G_{S}+Y_{S} \frac{\alpha_{r}}{2}\left(\Pi_{S}-1\right)^{2}
$$

The source of aggregate spending, $Y_{S}$, is private consumption, government consumption and resources spent to change prices. This is the last term in the equation above. In the conventional analysis, demand goes down at the ZLB because a reduction in inflation (dis-inflation) increases the real interest rate. This reduces private consumption, $C_{S}$, and thus aggregate demand $Y_{S}$. In this model, however, there is one additional force. As deflation is reduced, each firm "demands" more output to change prices. At relatively low values of inflation, this force dominates, which makes aggregate demand slope downwards. Figure 10 shows that this happens at about $-1 \%$ inflation. This effect is absent in the non-linear Calvo model. In fact, AD is almost linear in inflation. Hence the major difference in the results between the two models is the implication that the large resource costs of price adjustment have on aggregate demand. The AS curve also changes slope in the Rotemberg model with high enough deflation, i.e. output increases as inflation goes down. The reason is once again the high resource costs of changing prices. As inflation goes into negative territory, more resources go into changing prices. This reduces the consumption of the representative agent, thus increasing his marginal utility of income. This, in turn, will increase his labor supply, and increase aggregate supply.

The large resource costs of price changes rely heavily on the quadratic form of price adjustment and the fact that the value of $\alpha_{r}$ is very large. It seem implausible that at moderate levels of inflation, the actual output needed to change prices increases quadratically, corresponding to over $100 \%$ of all output at deflation levels in single digits. Indeed, since the costs are quadratic, then inflation of about $-10 \%$ is not technically feasible in the numerical experiment reported above as it would overwhelm the workforce. Since this particular mechanism is driving most of the non-linearities in the Rotemberg model it does not seem to be a good price-setting assumption to study extreme events of this form. ${ }^{17}$

There is, however, a simple modification of the Rotemberg model in which case the results from this model are similar to the Calvo model. Rotemberg's (1982) preferred interpretation of the quadratic costs faced by firms was not physical menu costs, but instead that "... there is a cost that captures the negative effect of price changes, particularly price increases on the reputation of firms". An alternative interpretation of the Rotemberg model is thus simply that these are costs

\footnotetext{
${ }^{17}$ Table 4 in the Appendix reports the multipliers in the Rotemberg model along with the resource costs.
} 
perceived by firms, and are taken into account only in the firm maximization problem, but do not correspond to direct cost of price changes. In this case, the model simplifies to

$$
\begin{gathered}
Y_{S}=\left\{G_{S}+(1-\bar{G})\left\{\left[1-\beta \mu \Pi_{S}^{-1}\right] \frac{\xi_{S}}{(1-\mu) \beta}\right\}^{\tilde{\sigma}}\right\} \\
{[1-\beta \mu]\left(\Pi_{S}-1\right) \Pi_{S}=\frac{\theta-1}{\alpha_{r}}\left(\frac{\theta}{\theta-1} \frac{\lambda\left\{Y_{S}-G_{S}\right\}^{\tilde{\sigma}^{-1}} Y_{S}^{\omega}}{\left(1-\tau_{S}^{w}\right)}-1\right)}
\end{gathered}
$$

Figure 12 compares the non-linear ('Modified Rotemberg') model to the linearized model. The Modified Rotemberg model is parameterized to match the GD scenario. ${ }^{18}$ As the figure shows, the non-linear model has no difficulty replicating this scenario, and the qualitative features of the model are now more in line with the non-linear and log-linearized Calvo model.

Figure 12: Modified Rotemberg Model versus the Linear Model

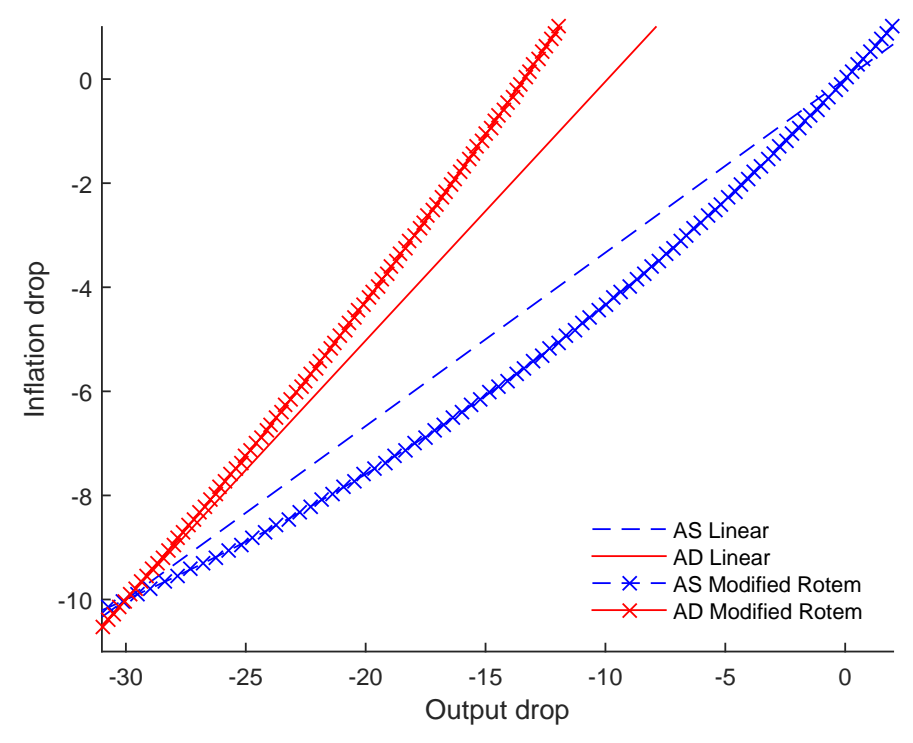

Ascari and Rossi (2012) have already suggested this mathematical variation of the Rotemberg model. In their model, while there are resource costs of changing prices borne by firms, these costs are rebated to the household lump sum. Accordingly, the costs do not show up in the economy's resource constraint. A complementary approach would be to abandon the somewhat unattractive assumption of quadratic costs of price adjustment, following the business cycle literature on investment adjustment costs. It has been recognized in the business cycle literature that quadratic costs of investment adjustment can lead to non-sensical conclusions for the same reason as here, large enough drop in investment lead to implausible adjustment costs. Christiano and Davis (2006, p. 13-14) resolve this by fitting a tenth degree polynomial, with standard

\footnotetext{
${ }^{18}$ Table 5 in the Appendix reports the calibrated parameters and the corresponding mutlipliers in the Modified Rotemberg model and contrast them with those of the Linearized model.
} 
Chebyshev interpolation that replicates the first order investment dynamics needed to explain the business cycle and implied by a quadratic adjustment function - yet at the same time implies plausible equilibrium resource adjustment costs. The same approach can be used here, but this is left for future research. ${ }^{19}$

Hence, the assumption of quadratic costs implies that the non-linear model yields solutions that are not be economically meaningful under extreme scenarios.

\section{Conclusion}

This paper studies the non-linear properties of the Calvo model at the ZLB. It also illustrates why the Rotemberg model delivers different results and argues that the economics behind what is driving those differences makes the Rotemberg model unattractive for analyzing extreme events. A modified Rotemberg model - arguably more in spirit with Rotemberg's original suggestion delivers very similar result as the Calvo model and the linearized model.

\section{References}

Aruoba, S Borağan, Pablo Cuba-Borda, and Frank Schorfheide. 2016. "Macroeconomic dynamics near the ZLB: A tale of two countries." National Bureau of Economic Research.

Ascari, Guido, and Lorenza Rossi. 2012. "Trend Inflation and Firms Price-Setting: Rotemberg Versus Calvo." The Economic Journal, 122(563): 1115-1141.

Benhabib, Jess, Stephanie Schmitt-Grohé, and Martin Uribe. 2001. "Monetary policy and multiple equilibria." American Economic Review, 167-186.

Benigno, Pierpaolo, and Michael Woodford. 2004. “Optimal monetary and fiscal policy: A linear-quadratic approach." In NBER Macroeconomics Annual 2003, Volume 18. 271-364. The MIT Press.

Bhattarai, Saroj, Gauti Eggertsson, and Raphael Schoenle. 2014. "Is increased price flexibility stabilizing? redux." National Bureau of Economic Research.

Blanchard, Olivier Jean, and Charles M Kahn. 1980. “The solution of linear difference models under rational expectations." Econometrica, 1305-1311.

Braun, R Anton, Lena M Körber, and Yuichiro Waki. 2016. "Some Unpleasant Properties of Loglinearized Solutions When the Nominal Rate is Zero." Bank of England working paper no 553.

Calvo, Guillermo A. 1983. "Staggered prices in a utility-maximizing framework." Journal of Monetary Economics, 12(3): 383-398.

\footnotetext{
${ }^{19}$ As these authors point out the assumption of the adjustment function being quadratic is arbitrary, and has usually been only made for simplicity in the context of non-linear models that are ultimately approximated by loglinear approximation. Taken literally, the non-linear counterpart then implies non-sensical investment adjustment costs.
} 
Christiano, Lawrence J, and Joshua M Davis. 2006. "Two flaws in business cycle accounting." National Bureau of Economic Research.

Christiano, Lawrence J, and Martin Eichenbaum. 2012. "Notes on linear approximations, equilibrium multiplicity and e-learnability in the analysis of the zero lower bound." Manuscript, Northwestern University.

Christiano, Lawrence J, Martin Eichenbaum, and Benjamin K Johannsen. 2016. "Does the New Keynesian Model Have a Uniqueness Problem?" Manuscript, Northwestern University.

Christiano, Lawrence, Martin Eichenbaum, and Sergio Rebelo. 2011. "When Is the Government Spending Multiplier Large?" Journal of Political Economy, 119(1): 78-121.

Denes, Matthew, and Gauti B. Eggertsson. 2009. "A bayesian approach to estimating tax and spending multipliers." FRB of New York Staff Report no. 403, , (403).

Denes, Matthew, Gauti B. Eggertsson, and Sophia Gilbukh. 2013. "Deficits, public debt dynamics and tax and spending multipliers." The Economic Journal, 123(566): F133-F163.

Eggertsson, Gauti. 2001. "Real government spending in a liquidity trap." Photocopy, Princeton University.

Eggertsson, Gauti B. 2010. “The paradox of toil." FRB of New York Staff Report no. 433.

Eggertsson, Gauti B. 2011. "What fiscal policy is effective at zero interest rates?" In NBER Macroeconomics Annual 2010, Volume 25. 59-112. University of Chicago Press.

Eggertsson, Gauti B., and Michael Woodford. 2003. "The Zero Bound on Interest Rates and Optimal Monetary Policy." Brookings Papers on Economic Activity, 139-211.

Fernández-Villaverde, Jesús, Grey Gordon, Pablo Guerrón-Quintana, and Juan F RubioRamirez. 2015. "Nonlinear adventures at the zero lower bound." Journal of Economic Dynamics and Control, 57: 182-204.

Gertler, Mark, and John Leahy. 2008. "A Phillips Curve with an Ss Foundation." Journal of Political Economy, 116(3).

McCallum, Bennett T. 2007. "E-stability vis-a-vis determinacy results for a broad class of linear rational expectations models." Journal of Economic dynamics and control, 31(4): 1376-1391.

Mertens, Karel R.S.M., and Morten O. Ravn. 2014. "Fiscal policy in an expectations-driven liquidity trap." The Review of Economic Studies.

Miao, Jianjun, and Phuong V Ngo. 2016. "Does Calvo Meet Rotemberg at the Zero Lower Bound?" Mimeo, Cleveland State University.

Nakata, Taisuke, and Sebastian Schmidt. 2015. "Conservatism and liquidity traps."

Rotemberg, Julio J. 1982. "Sticky prices in the United States." The Journal of Political Economy, 1187-1211.

Schmitt-Grohé, Stephanie, and Martın Uribe. 2016. "Liquidity Traps and Jobless Recoveries."

Woodford, Michael. 2003. Interest and Prices: Foundations of a Theory of Monetary Policy. Princeton University Press. 
Woodford, Michael. 2011. "Simple Analytics of the Government Expenditure Multiplier." American Economic Journal: Macroeconomics, 3(1): 1-35.

Yun, Tack. 1996. "Nominal price rigidity, money supply endogeneity, and business cycles." Journal of Monetary Economics, 37(2-3): 345-370. 


\section{A Appendix}

A.1 System of equations for the Non-linear Calvo model under two-state Markov chain assumption

1. Euler

$$
1=\beta(1-\mu)\left(\frac{C_{L}}{C_{S}}\right)^{-1 / \tilde{\sigma}} \frac{1}{\xi_{S}} \frac{1}{\Pi_{L}}+\beta \mu \frac{1}{\Pi_{S}}
$$

where $C_{L}=1-\bar{G}$, and $\Pi_{L}=1$.

2. NK Phillips Curve

$$
\begin{aligned}
K_{S} & =\frac{\theta}{\theta-1} \frac{\lambda \xi_{S}}{\left(1-\tau_{S}^{w}\right)} Y_{S}^{1+\omega}+\alpha \beta(1-\mu) K_{L}+\alpha \beta \mu \Pi_{S}^{\theta(1+\omega)} K_{S} \\
F_{S} & =\xi_{L} C_{S}^{-\frac{1}{\tilde{\sigma}}} Y_{S}+\alpha \beta(1-\mu) F_{L}+\alpha \beta \mu \Pi_{S}^{(\theta-1)} F_{S} \\
\frac{K_{S}}{F S} & =\left(\frac{1-\alpha \Pi_{S}^{\theta-1}}{1-\alpha}\right)^{\frac{1+\omega \theta}{1-\theta}}
\end{aligned}
$$

where $\lambda \equiv \frac{\theta-1}{\theta}\left(1-\tau_{w}\right)(1-\bar{G})^{\tilde{\sigma}^{-1}}$.

3. Monetary Policy Rule:

$$
i_{t}=i_{z l b} \text {, in the short run }
$$

4. Resource Constraint

$$
Y_{t}=C_{t}+G_{t}
$$

5. Fiscal Policy rule: Normal Government Spending $\bar{G}$ is calibrated at $0.2(20 \%$ of steady state GDP). Labor Taxes $\bar{\tau}^{w}$. are calibrated at 0.3 . To calculate fiscal multipliers: when ZLB is binding, $G_{S}>\bar{G}$. For Paradox of toil, $\tau_{S}^{w}<\bar{\tau}^{w}$.

6. Preference Shock

$$
\xi_{S}<\xi_{L} \equiv 1
$$

\section{A.2 Mapping the shock in the linear Calvo with the non-linear Calvo}

$$
\begin{aligned}
\hat{r}_{S}^{e} & =\log \beta^{-1}+(1-\mu) \log \xi_{S} \\
\Longrightarrow \log \xi_{S} & =\frac{\left(r_{S}^{e}-\log \beta^{-1}\right)}{(1-\mu)} \\
\Longrightarrow \xi_{S} & =\exp \left(\frac{\left(r_{S}^{e}-\log \beta^{-1}\right)}{(1-\mu)}\right)
\end{aligned}
$$

Defines a correspondance between $\xi_{S}$ and $\hat{r}_{S}^{e} a$

\section{A.3 Determinacy in the non-linear model}

Under the two state assumption (with a binding zlb), the dynamic system can be written as: 
1. Euler

$$
\begin{aligned}
0 & =\beta \mu \mathbb{E}_{\mathrm{t}}^{S}\left[\left(\frac{Y_{t+1}^{S}-G^{S}}{Y_{t}^{S}-G^{S}}\right)^{-1 / \tilde{\sigma}} \frac{1}{\Pi_{t+1}^{S}}\right]+\beta(1-\mu)\left[\left(\frac{1}{Y_{t}^{S}-G^{S}}\right)^{-1 / \tilde{\sigma}} \frac{1}{\xi^{S}}\right]-1 \\
& \equiv f^{1}\left(\mathbb{E}_{\mathrm{t}}^{S} Y_{t+1}^{S}, \mathbb{E}_{\mathrm{t}}^{S} \Pi_{t+1}^{S}, Y_{t}^{S}\right)
\end{aligned}
$$

\section{NK Phillips Curve}

$$
\begin{aligned}
0 & =\frac{\theta}{\theta-1} \frac{\lambda \xi^{S}}{\left(1-\tau_{t}^{w}\right)}\left(Y_{t}^{S}\right)^{1+\omega}+\alpha \beta(1-\mu) K^{L}+\alpha \beta \mu \mathbb{E}_{\mathrm{t}}^{S}\left[\left(\Pi_{t+1}^{S}\right)^{\theta(1+\omega)} K_{t+1}^{S}\right]-K_{t}^{S} \\
& \equiv f^{2}\left(\mathbb{E}_{\mathrm{t}}^{S} \Pi_{t+1}^{S}, \mathbb{E}_{\mathrm{t}}^{S} K_{t+1}^{S}, Y_{t}^{S}, K_{t}^{S}\right) \\
0 & =\xi^{S}\left(Y_{t}^{S}-G^{S}\right)^{-\frac{1}{\tilde{\sigma}}} Y_{t}^{S}+\alpha_{c} \beta(1-\mu) F^{L}+\alpha \beta \mu \mathbb{E}_{\mathrm{t}}^{S}\left[\left(\Pi_{t+1}^{S}\right)^{(\theta-1)} F_{t+1}^{S}\right]-F_{t}^{S} \\
& \equiv f^{3}\left(\mathbb{E}_{\mathrm{t}}^{S} \Pi_{t+1}^{S}, \mathbb{E}_{\mathrm{t}}^{S} F_{t+1}^{S}, Y_{t}^{S}, F_{t}^{S}\right) \\
0 & =\frac{K_{t}^{S}}{F_{t}^{S}}-\left(\frac{1-\alpha\left(\Pi_{t}^{S}\right)^{\theta-1}}{1-\alpha}\right)^{\frac{1+\omega \theta}{1-\theta}} \equiv f^{4}\left(\Pi_{t}^{S}, K_{t}^{S}, F_{t}^{S}\right)
\end{aligned}
$$

having substituted in the resource constraint and assuming that $G_{t+1}^{S}=G_{t}^{S}=G^{S}$. Observe that the expectation of each variable conditional on that the shock will remain in the low "shortrun" state in the next period is denoted by $\mathbb{E}^{S}$. Writing the system in this way, this represents a regular rational expectation system that can be solved via standard methods, e.g. using Blanchard and Kahn (1980).

Linearizing this system of equations yields:

$$
\begin{array}{r}
{\left[\frac{\partial f^{1}}{\partial \mathbb{E}_{\mathrm{t}}^{S} Y_{t+1}^{S}}\right]_{s s} \mathbb{E}^{S} \hat{Y}_{t+1}^{S}+\left[\frac{\partial f^{1}}{\partial Y_{t}^{S}}\right]_{s s} \hat{Y}_{t}^{S}+\left[\frac{\partial f^{1}}{\partial \mathbb{E}_{\mathrm{t}}^{S} \Pi_{t+1}^{S}}\right]_{s s} \mathbb{E}_{t}^{S} \pi_{t+1}^{S}=0} \\
{\left[\frac{\partial f^{2}}{\partial K_{t}^{S}}\right]_{s s} k_{t}^{S}+\left[\frac{\partial f^{2}}{\partial Y_{t}^{S}}\right]_{s s} \hat{Y}_{t}^{S}+\left[\frac{\partial f^{2}}{\partial \Pi_{t}^{S}}\right]_{s s} \pi_{t}^{S}+\left[\frac{\partial f^{2}}{\partial \mathbb{E}_{\mathrm{t}}^{S} K_{t+1}^{S}}\right]_{s s} \mathbb{E}^{S} \hat{K}_{t+2}^{S}=0} \\
{\left[\frac{\partial f^{3}}{\partial F_{t}^{S}}\right] \hat{F}_{t}^{S}+\left[\frac{\partial f^{3}}{\partial Y_{t}^{S}}\right]_{s s} \hat{Y}_{t}^{S}+\left[\frac{\partial f^{3}}{\partial \Pi_{t}^{S}}\right]_{s s} \pi_{t}^{S}+\left[\frac{\partial f^{3}}{\partial \mathbb{E}_{\mathrm{t}}^{S} F_{t+1}^{S}}\right]_{s s} \mathbb{E}_{t}^{S} \hat{F}_{t+1}^{S}=0} \\
{\left[\frac{\partial f^{4}}{\partial K_{t}^{S}}\right]_{s s} \hat{K}_{t}^{S}+\left[\frac{\partial f^{4}}{\partial F_{t}^{S}}\right]_{s s} \hat{F}_{t}^{S}+\left[\frac{\partial f^{4}}{\partial \Pi_{t}^{S}}\right]_{s s} \pi_{t}^{S}=0}
\end{array}
$$

where small letters $\left\{\hat{Y}_{t}^{S}, \pi_{t}^{S}, \hat{K}_{t}^{S}, \hat{F}_{t}^{S}\right\}$ indicate deviations of the variables from the solution around which the equations are linearized. This system of equations is determinate if there are at least 3 unstable eigenvalues outside of the unit circle. Numerically simulations (using reds and solds) suggest that the second equilibrium fails to meet the determinacy conditions and hence is locally unstable. Henceforth, the paper only investigates the properties of the stable equilibrium (in this case, it is the one that produces 30\% drop in Output and 10\% drop in inflation ). 


\section{A.4 Determinacy in the linear model - Proposition 3 from Eggertsson (2011)}

Lemma 1. An approximate equilibrium defined by the collection of stochastic processes $\left\{\hat{y}_{S}, \pi_{S}\right\}$ at zero interest rates is a locally unique bounded equilibrium, for a given path of these variables after the ZLB stops binding and a given value of $r_{S}^{e}$. if $C 1$ and $C 2$ hold, where

$$
\begin{gathered}
r_{S}^{e}<-\Gamma_{\tau^{w}} \tau_{S}^{\hat{w}}-\Gamma_{G} \hat{g}_{S} \\
L(\mu) \equiv(1-\mu)(1-\mu \beta)-\kappa \mu \sigma>0
\end{gathered}
$$

\section{A.5 Priors used for likelihood estimation}

The same priors are used across all likelihood maximization procedures. These were first used by Denes and Eggertsson (2009) and the consequent literature. Table 3 reproduces them.

Table 3: Priors for the structural parameters and the shocks

\begin{tabular}{|r|r|r|r|r|}
\hline & distribution & Prior 5\% & Prior 50\% & Prior 95\% \\
\hline$\alpha$ & beta & 0.5757 & 0.6612 & 0.7402 \\
\hline$\beta$ & beta & 0.9949 & 0.9968 & 0.9981 \\
\hline $1-\mu$ & beta & 0.0198 & 0.074 & 0.1788 \\
\hline$\sigma^{-1}$ & gamma & 1.2545 & 1.9585 & 2.8871 \\
\hline$\omega$ & gamma & 0.1519 & 0.82 & 2.4631 \\
\hline$\theta$ & gamma & 3.7817 & 7.6283 & 13.4871 \\
\hline$r_{S}^{e}$ & gamma & 0.0036 & 0.0094 & 0.0196 \\
\hline
\end{tabular}

\section{A.6 Multipliers in the Rotemberg Model}

Table 4 reports the multipliers in the Rotemberg model and compares them with those obtained in the Modified Rotemberg model. Notes below the table explain in detail the parametrization used. The core point is that if there is physical resource costs of changing prices (e.g. menu costs) that take on a quadratic form, then the non-linear model is unable to produce a significant drop in output and inflation.

Table 4: Multipliers in the Modified Rotemberg versus the Rotemberg Model

\begin{tabular}{|l|l|l|l|l|}
\hline Scenario & \multicolumn{2}{|c|}{ Great Depression } & \multicolumn{2}{c|}{ Great Recession } \\
\hline \hline Model & Rotemberg & Mod. Rotem. & Rotemberg & Mod. Rotem. \\
\hline$\hat{Y}$ & $-1.5 \%$ & $-30 \%$ & $-5.2 \%$ & $-10 \%$ \\
\hline$\pi$ & $-4.6 \%$ & $-10 \%$ & $-1.5 \%$ & $-2 \%$ \\
\hline$\frac{\partial \hat{Y}}{\partial G}$ & 0.4107 & 1.7684 & 0.6977 & 1.2455 \\
\hline$\frac{\partial \hat{Y}}{\partial \tau^{w}}$ & -0.5542 & 0.2589 & -0.2363 & 0.0835 \\
\hline
\end{tabular}

a The parameters used in calculating these numbers are reported in Columns $1 \& 3$ of table 5. They match the Great Depression and the Great Recession Scenarios for the Modified Rotemberg Model.

\section{A.7 Parameters and Multipliers in the Modified Rotemberg Model}


Table 5: Parameterizations for the Modified Rotemberg and the Linearized Model

\begin{tabular}{|l|l|l|l|l|}
\hline \multirow{2}{*}{ Scenario } & \multicolumn{2}{|c|}{ Great Depression } & \multicolumn{2}{c|}{ Great Recession } \\
\hline \hline Model & Mod. Rotem. & Linear & Mod. Rotem. & Linear \\
\hline$\hat{Y}$ & $-30 \%$ & $-30 \%$ & $-10 \%$ & $-10 \%$ \\
\hline$\pi$ & $-10 \%$ & $-10 \%$ & $-2 \%$ & $-2 \%$ \\
\hline$\frac{\partial \hat{Y}}{\partial G}$ & 1.7684 & 2.2168 & 1.2455 & 1.1828 \\
\hline$\frac{\partial \hat{Y}}{\partial \tau^{w}}$ & 0.2589 & 0.9953 & 0.0835 & 0.1499 \\
\hline$\alpha$ & 0.7720 & 0.7721 & 0.7667 & 0.7871 \\
\hline$\beta$ & 0.9957 & 0.9969 & 0.9970 & 0.9970 \\
\hline$\sigma^{-1}$ & 1.2496 & 1.1649 & 1.1849 & 1.2900 \\
\hline$\omega$ & 1.7109 & 1.7465 & 2.2316 & 1.7415 \\
\hline$\theta$ & 10.4726 & 13.1190 & 14.4678 & 13.6012 \\
\hline $1-\mu$ & 0.0910 & 0.0965 & 0.1326 & 0.1393 \\
\hline$r_{S}^{e}$ & -0.0193 & -0.0111 & -0.0155 & -0.0136 \\
\hline
\end{tabular}

$\alpha$ reported here is the Calvo parameter : 1 - probability of price adjustment. We estimate this $\alpha$ in our likelihood maximization in order to use the same priors across all the specifications. It is straightforward to back out the Rotemberg $\alpha_{r}$ using the formula reported in the main text. 